\title{
A 10-MHz FREE-FREE BEAM MICROMECHANICAL RESONATOR FABRICATION PROCESS USING SURFACE-MICROMACHINED TECHNOLOGY
}

\author{
TAN-LOC NGUYEN \\ Faculty of Electronics Technology, Industrial University of Ho Chi Minh City \\ nguyentanloc@iuh.edu.vn
}

\begin{abstract}
The fabrication process for the designed MEMS resonator using surface-micromachined technology is presented in this paper. A 10-MHz Free-Free beam MEMS resonator is designed to vibrate in the second-mode shape, which is significant improvement compare to the fundamental mode. The design showed a $Q$ value as high as 75,000, which is significant improvement compared to 8,400 VHF F-F beam MEMS resonator by $\mathrm{K}$. Wang; and very low motional resistance $(18 \mathrm{k} \Omega)$. The surface-micromachined technology is used as the standard process for the design. The process is briefly described from the layout design to the experimental fabricated device.

Keywords. MEMS resonator, surface-micromachined technology, second-mode shape, fabrication process.

\section{INTRODUCTION}

In recent years, much research has taken place in design and fabrication for MEMS. Clamed-Clamed (CC) beam MEMS resonators have been presented for VHF range applications [1]. However, as a result of the large stiffness, the total energy loss increased due to the vibration, which made the lower resonator Q. In order to achieve high $\mathrm{Q}$, many other types of resonator geometries are designed. The first Free-Free (FF) beam resonator operating at VHF range was reported in 2000 [2, 3]. With anchor loss optimization technique, the high-stiffness VHF resonator based on surface-micromachined fabrication process is demonstrated the quality factor Q as high as 8400. The higher-mode F-F beam MEMS resonators have been investigated to make use of the large dimensions, which offer several advantages such as low series motional resistance $\mathrm{R}_{\mathrm{x}}$; high dynamic range and power handling, etc [4].

Based on the surface-micromachined technology, this paper presents the design and fabrication process of a $10 \mathrm{MHz}$ second-mode F-F beam resonator. First of all, the theory of the designed resonator is introduced. Next, the FEM simulation is done to obtain the resonator parameters. The designed resonator showed a Q's as high as 74,800 and a low serial motional resistance $R_{x}$ of $18 \mathrm{k} \Omega$ at $10 \mathrm{MHz}$ resonance frequency. Finally, the fabrication process based on surface-micromachined technology is briefly described.
\end{abstract}

\section{FREE-FREE BEAM MEMS RESONATOR DESIGN}

\subsection{Mechanical Model and Design Theory}

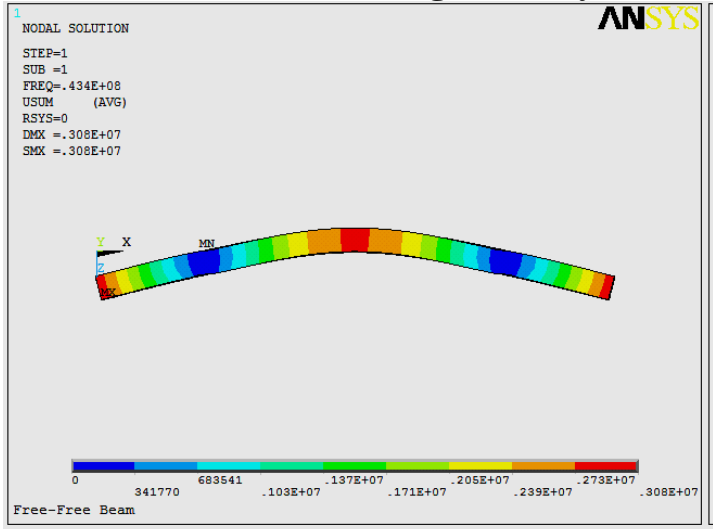

(a)

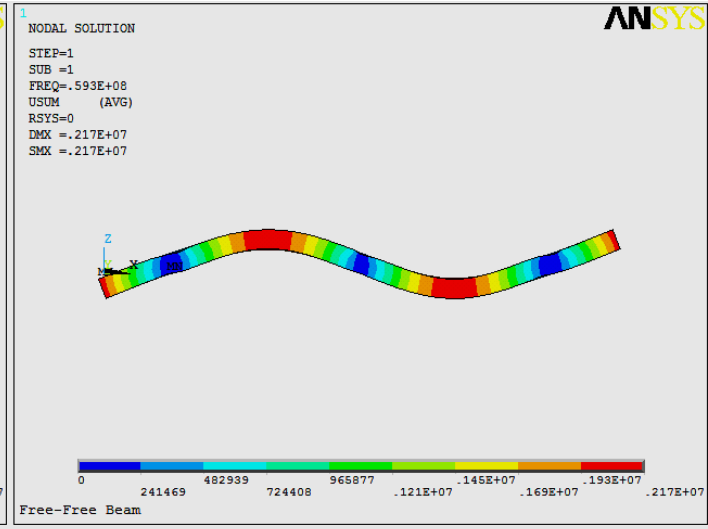

(b)

Figure 1: Mode shape simulations of a Free-Free beam resonator

(a) Fundamental mode; and (b) Second-mode 
The second-mode F-F beam resonator is designed to operate at $10-\mathrm{MHz}$ frequency. The mode shape simulations are illustrated in Figure 1. The largest vibration amplitude is highlighted in red color and the blue color shows the smallest vibration or zero point.

The motion equation of F-F beam can be given as

$$
z(y)=B\left[\frac{A}{B}(\cosh k y+\cos k y)+(\sinh k y+\sin k y)\right]
$$

In order to obtain high performance, the resonator is designed to vibrate at second-mode shape and its structure should be designed following the calculated points as shown as Figure 2, which illustrated electrode placements (from L11 to L12 and from L21 to L22), mode shape, and located nodal points.

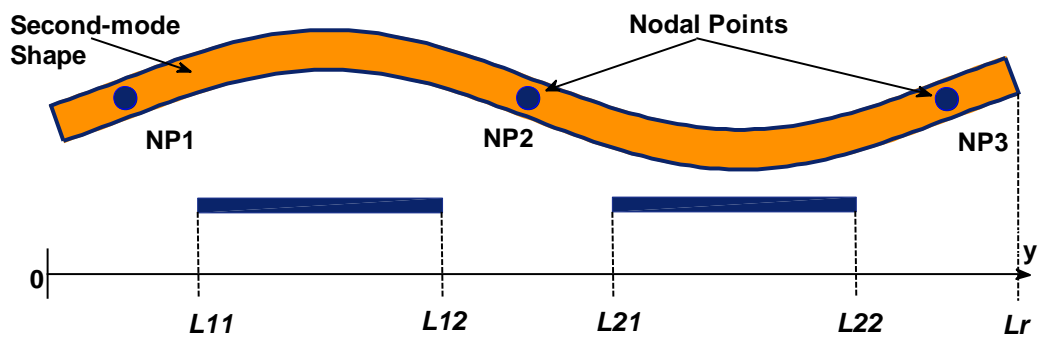

Figure 2. Cross-section view of a second mode F-F beam resonator.

The support structure is defined using FEM simulation. The simulation and calculations of the resonator nodal points are shown in Figure 3 and Figure 4, respectively.

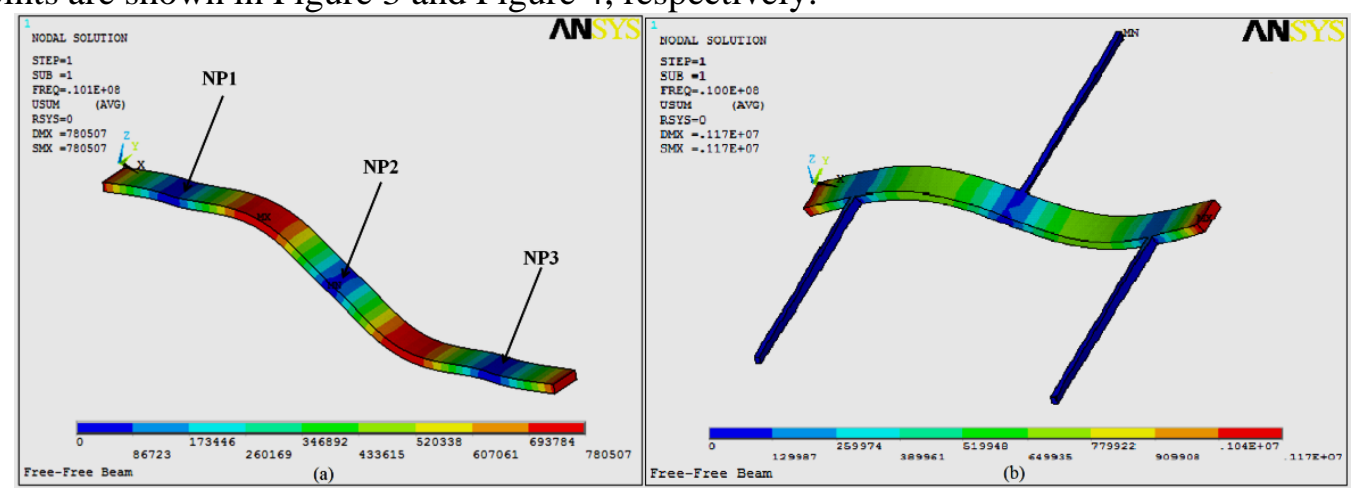

Figure 3. (a) The Second-mode shape and (b) The attachment of support beam structures.

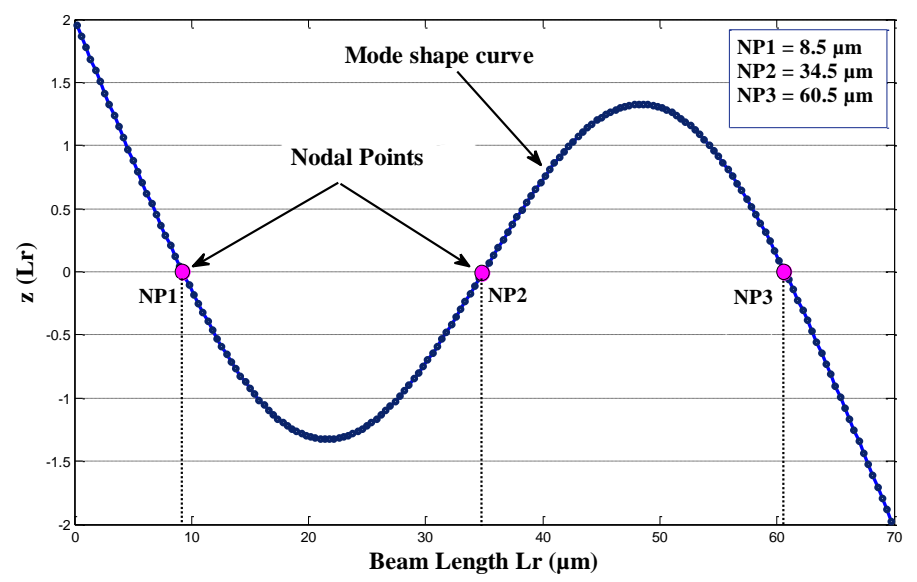

Figure 4. Nodal points calculation of a 10-MHz F-F beam MEMS resonator $(\mathrm{Lr}=69 \mu \mathrm{m})$.

\subsection{Equivalent Circuit Model}

By using the mechanical-to-electrical analogy in Table 1 [5], the equivalent circuit model for the designed F-F beam MEMS resonator can be established as shown in Figure 5.

Table 1. Mechanical-to-Electrical Analogy. 


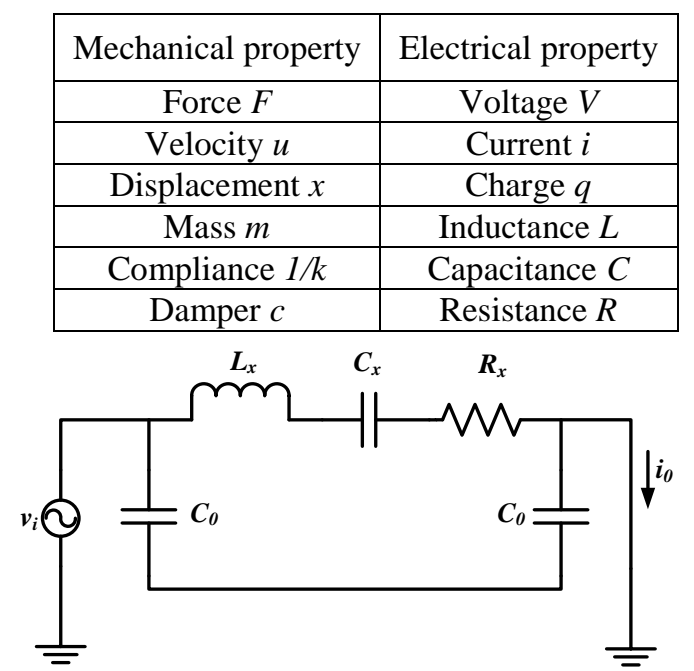

Figure 5. Equivalent circuit models of F-F beam resonator.

where $L_{x}, C_{x}$, and $R_{x}$ are the electrical equivalent parameters of the designed resonator and it can be given as

$$
L_{x}=\frac{m_{e q}}{\eta^{2}}, R_{x}=\frac{\sqrt{k_{e q} m_{e q}}}{Q \eta^{2}}=\frac{c_{e q}}{\eta^{2}}, C_{x}=\frac{\eta^{2}}{k_{e q}}
$$

$C_{0}$ is the static capacitance and it can be calculated as

where $W$ is the width of the F-F beam.

\subsection{Resonator Parameters}

Based on the surface-micromachined technology, the parameters of MEMS resonator are simulated and calculated as listed in Table 2.

Table 2. The designed parameters of the proposed resonator.

\begin{tabular}{|c|c|c|c|}
\hline Parameter & Source & Value & Unit \\
\hline Resonance frequency, $f_{0}$ & Designed & 10 & $\mathrm{MHz}$ \\
\hline Beam length, $L_{r}$ & Reference [7] & 69 & $\mu \mathrm{m}$ \\
\hline Beam width, $W_{r}$ & Designed & 8 & $\mu \mathrm{m}$ \\
\hline Beam thickness, $h$ & Process & 2 & $\mu \mathrm{m}$ \\
\hline Support beam length, $L_{S}$ & Reference [7] & 50 & $\mu \mathrm{m}$ \\
\hline Support beam width, $W_{S}$ & Designed & 1 & $\mu \mathrm{m}$ \\
\hline Electrode width, $W_{e}\left(L_{12}-L_{11}\right)$ & Designed & 13 & $\mu \mathrm{m}$ \\
\hline Electrode-to-resonator gap, $d_{0}$ & Process & 0.3 & $\mu \mathrm{m}$ \\
\hline Nodal point $1, N P 1$ & Equation $(1)$ & 8.5 & $\mu \mathrm{m}$ \\
\hline Nodal point 2, NP2 & Equation $(1)$ & 34.5 & $\mu \mathrm{m}$ \\
\hline Nodal point 3, NP3 & Equation $(1)$ & 60.5 & $\mu \mathrm{m}$ \\
\hline Young's modulus, $E$ & Material property & 180 & $\mathrm{GPa}$ \\
\hline Poisson ratio, $v$ & Material property & 0.29 & --- \\
\hline Density of polysilicon, $\rho$ & Material property & 2330 & $\mathrm{~kg} / \mathrm{m}^{3}$ \\
\hline DC bias voltage, $V_{p}$ & Designed & 50 & $\mathrm{~V}$ \\
\hline
\end{tabular}

The frequency response of the resonator under 50V DC-bias and $1 \mathrm{~V}$ ac-drive voltages is illustrated in Figure 8. The result shows the quality factor as high as 74800 , which is nine times $(9 \mathrm{X})$ higher than the previous fundamental mode reported for F-F beam resonator [3] 


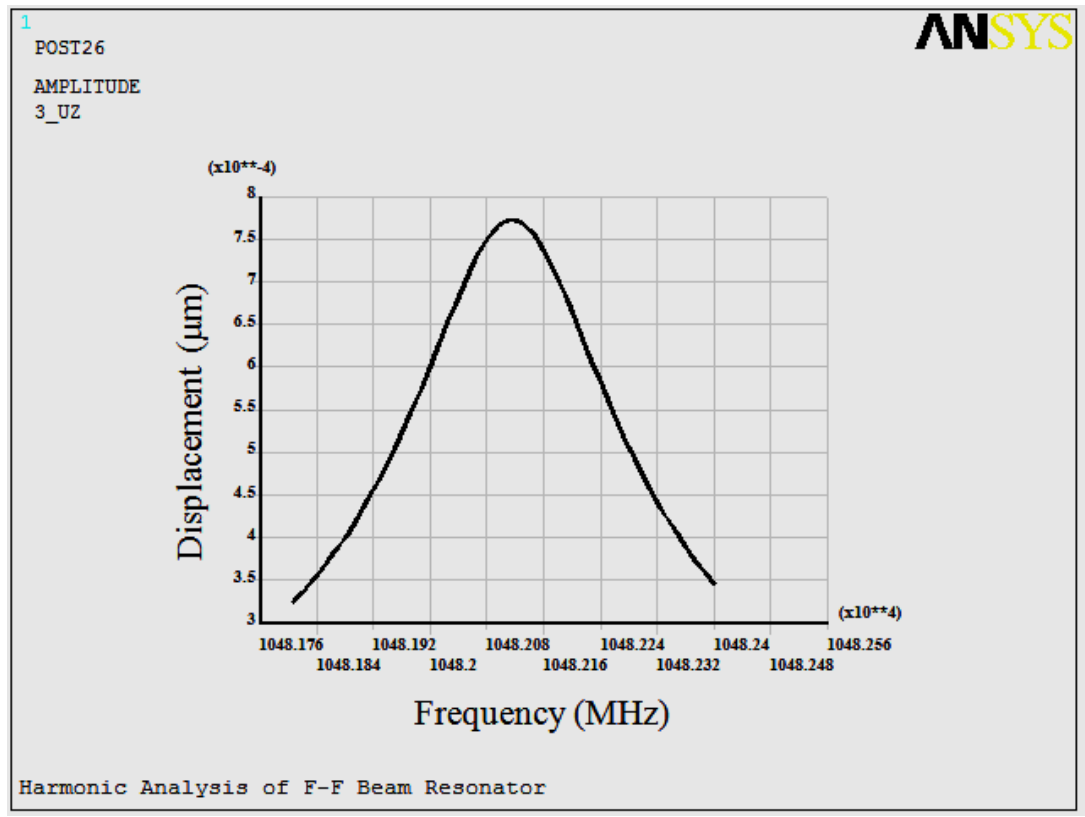

Figure 6. Frequency response of F-F beam MEMS resonator.

\section{SURFACE-MICROMACHINED PROCESS}

The proposed MEMS resonator is designed based on surface-micromachined technology, which is available on the market. The fabrication process for the resonator in this work is as follow steps:

\subsection{Process Flow}

MEMS surface micromachining process begins with isolation layers formed via deposition of $2 \mu \mathrm{m}$ silicon dioxide and $0.35 \mu \mathrm{m}$ low-pressure chemical vapor deposition (LPCVD) $\mathrm{Si}_{3} \mathrm{~N}_{4}$ over a starting silicon wafer. Next, the polysilicon layer is deposited to form an electrode layer. The electrode layer structure is then obtained using wet-etching as shown in Figure 7.

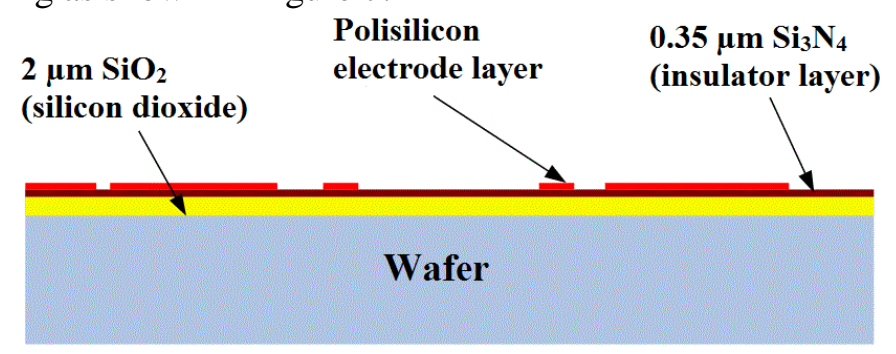

Figure 7. Electrode layer process of F-F beam MEMS resonator

Then, an LPCVD sacrificial oxide layer is deposited on the surface of the electrode layer. This layer of PSG is removed at the end of the process to free the first mechanical layer of polysilicon. A structural polysilicon layer is deposited on the top of the sacrificial layer to form the structural polysilicon of the resonator as shown in Figure 8.

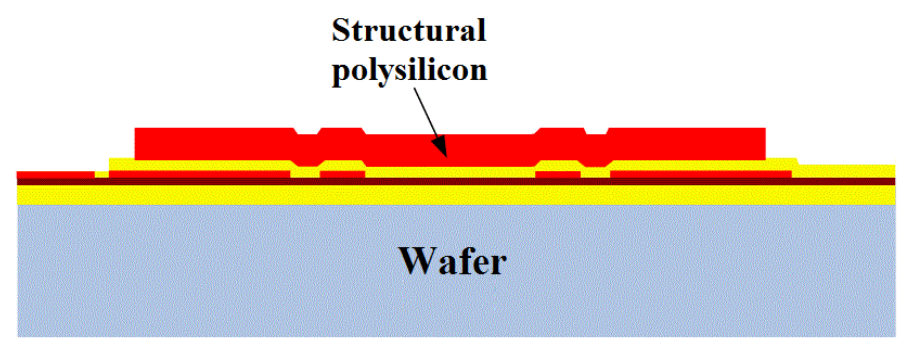

Figure 8. Structural polysilicon process of F-F beam MEMS resonator

Finally, a metal layer is deposited on the electrode to form a resonator PAD. The sacrificial layer is then released to complete the fabrication process flow for the designed F-F beam MEMS resonator as shown in Figure 9. 


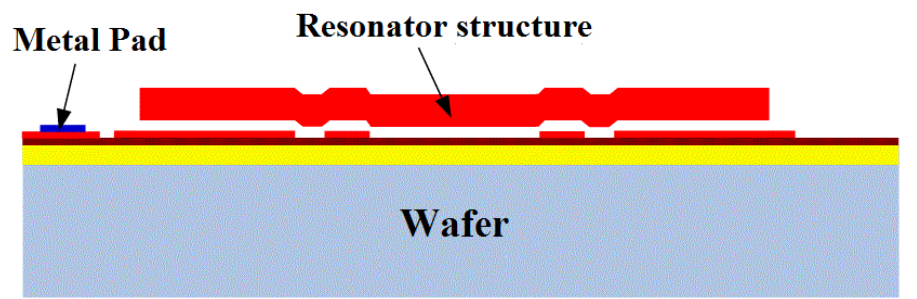

\subsection{Mask Layout}

Figure 9. Depositing a metal pad and releasing the sacrificial layer

It requires four lithographic masks for F-F beam MEMS resonator layout. During the processes, the positive photoresist, which is included on the electrode layer, is more easily removed. Therefore, the opaque areas under the photoresist layer are retained in the substrate while the exposed areas are removed by using wetetching. The electrode mask layer can be designed as illustrated in Figure 10. In mask layout, we need to align the cross on each layer. As shown, the second cross layer namely; " $2 \mathrm{~W}$ " is reserved for the sacrificial layer of the second mask layer. And the third cross layer; namely " $3 \mathrm{~W}$ " is the structural polysilicon layer of the third mask layer.

The second mask layer is the sacrificial oxide layer, using negative photoresist. The areas that without light will be etched and removed from the substrate as shown in Figure 11. A, B, and C areas are placed for the bias electrode, the RF input and RF output. Finally, a metal pad is deposited on the electrode layer to form the electrical PAD connection.

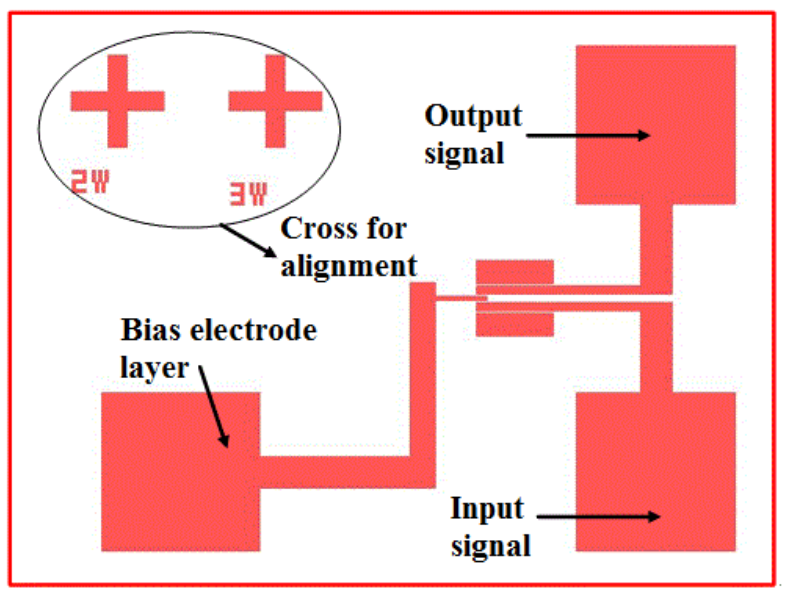

Figure 10. Electrode mask layer

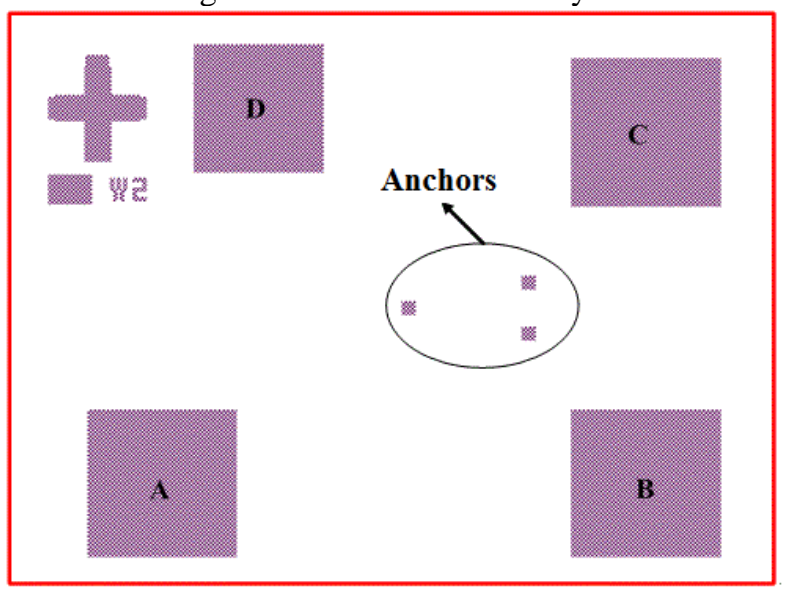

Figure 11. Sacrificial mask layer

In addition, the sacrificial mask layer also includes the regional and cross-anchor alignment. Surface micromachined technology allows an error of $2 \mu \mathrm{m}$ for cross alignment of each mask layer. Therefore, a D regional is released on the cover of the first cross alignment layer " $3 \mathrm{~W}$ " as shown in Figure 12. 
The misalignment of the cross alignment between two mask layers may be caused an error of $2 \mu \mathrm{m}$. Therefore, the width of cross alignment of the second layer is at least $2 \mu \mathrm{m}$ larger than the first cross-layer; namely $\Delta \mathrm{l}=\mathrm{l}_{2}-\mathrm{l}_{1}>2 \mu \mathrm{m}$. In this layout, $\Delta \mathrm{l}=10 \mu \mathrm{m}$ with $5 \mu \mathrm{m}$ on each side.

The third mask layer is the main structure of the resonator, using positive photoresist, three areas (1), (2), and (3) can be done by depositing a $2 \mu \mathrm{m}$ doped polysilicon on the sacrificial oxide layer. The metal layer is then deposited and patterned directly on the electrode layer to form the metal PAD of the resonator. "W3" and the first layer of " $3 \mathrm{~W}$ " are aligned. " $4 \mathrm{~W}$ " is reserved for the cross alignment of the fourth layer.
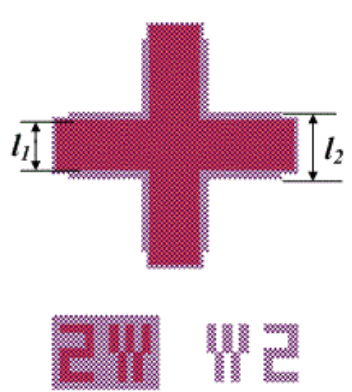
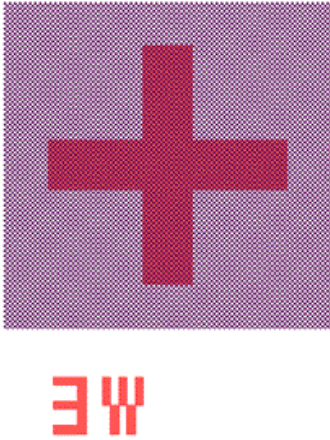

Figure 12. Mask layout for cross alignment

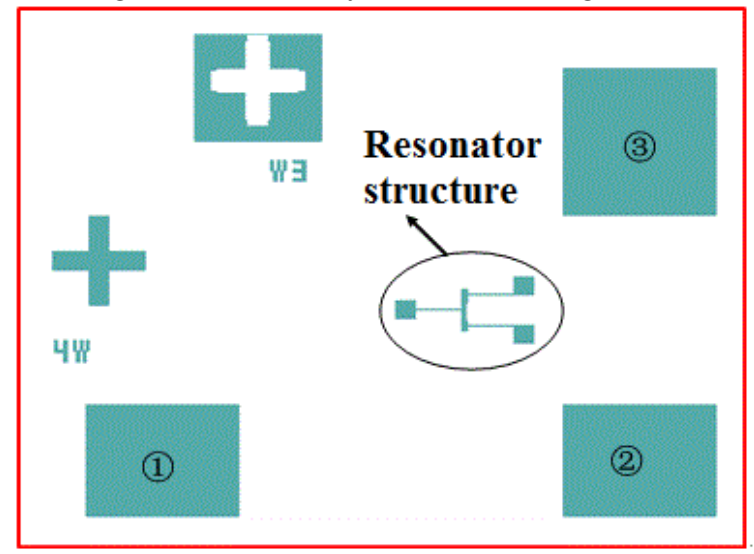

Figure 13. Structural polysilicon mask layer

The fourth mask layer is a metal PAD layer, which is deposited and patterned using positive photoresist. The layout of this mask layer includes three metal PAD areas and a cross alignment "W4" as shown in Figure 14.

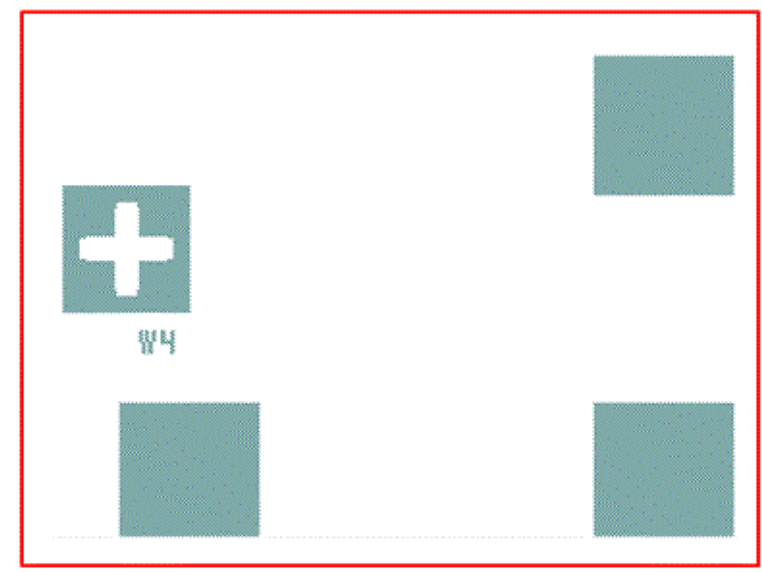

Figure 14. Metal mask layer

Therefore, the final layout resonator is illustrated as shown in Figure 15 


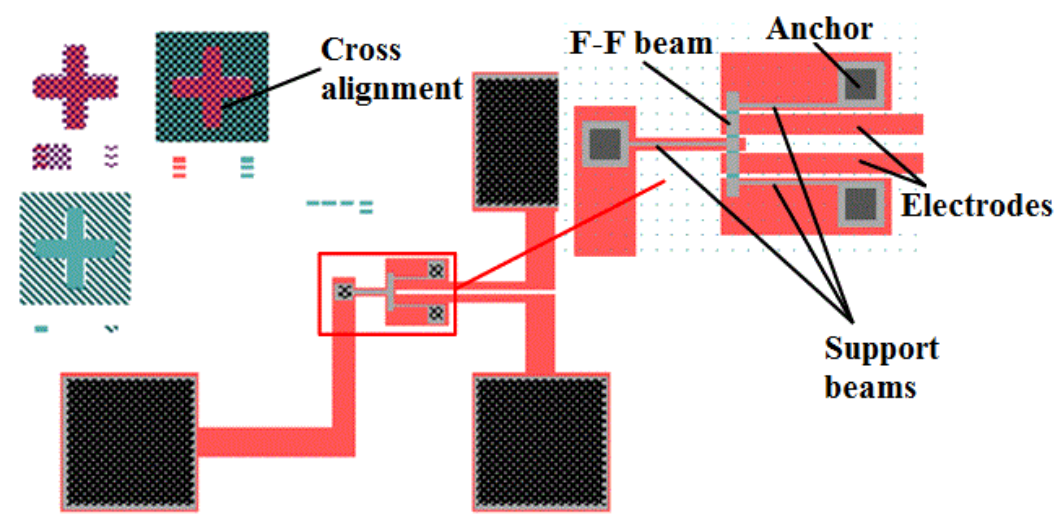

\subsection{Anchor Layout}

Figure 15. F-F beam resonator layout

In order to get the electrical connection between the resonance beam and the electrodes, a DC-bias voltage is directly applied to the resonant beam through the anchor. The anchor process of the resonator is shown in Figure 16, which can be divided into four steps:

(1) depositing a polysilicon electrode layer

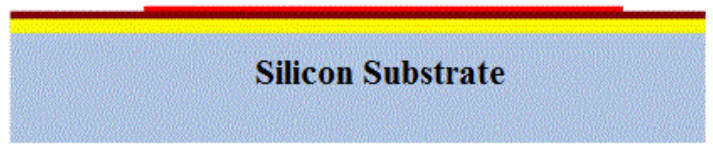

(2) depositing a sacrificial layer and etching the anchor areas

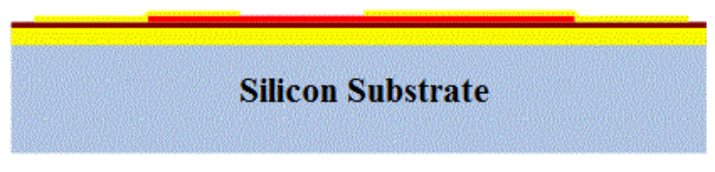

(3) depositing $2 \mu \mathrm{m}$ polysilicon structure layer over the sacrificial layer
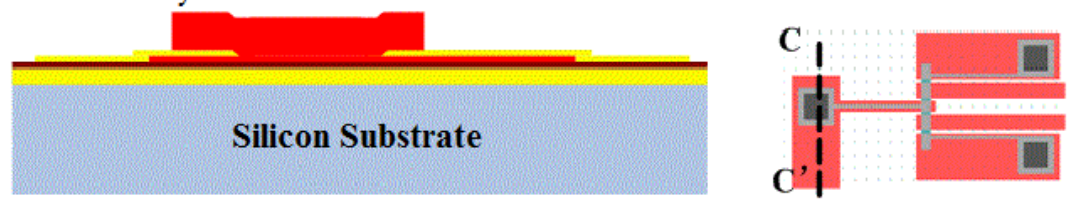

Figure 16. Resonator anchor structure process

(1) depositing a polysilicon electrode layer;

(2) depositing and etching a silicon oxide sacrificial layer to form the anchor areas;

(3) depositing $2 \mu \mathrm{m}$ polysilicon structure layer; the anchor is then directly connected to the electrode layer;

(4) releasing the sacrificial layer and complete the process.

\subsection{Processing Results}

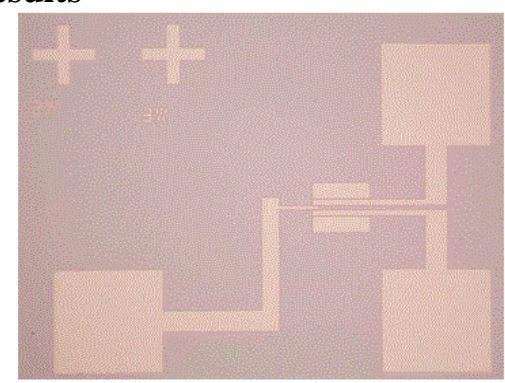

(a)

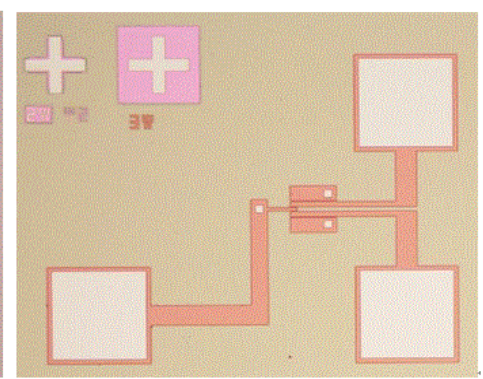

(b) 


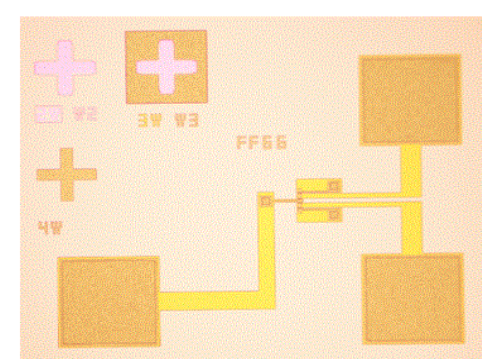

(c)

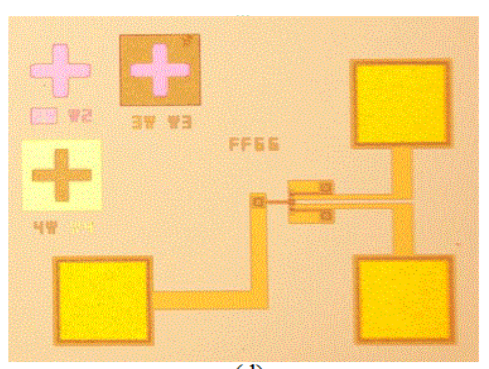

(d)

Figure 17. Microscopic layout images of the F-F beam MEMS resonator

(a) the bottom of electrode layer ; (b) the sacrificial oxide layer; (c) the structural polysilicon layer; and (d) metal pad layer

Figure 17 shows the images of each layer after processing. Figure 17(a) shows the bottom of electrode layer. The sacrificial layer is shown in Figure 17(b). Figure 17(c) shows the processing result of the structural polysilicon layer. And Figure 17(d) shows the processing result of metal pad layer.

After releasing the sacrificial layer, the resonator was cut dicing as illustrated in Figure 18. The SEM images of the F-F beam MEMS resonator was presented in Figure 19.

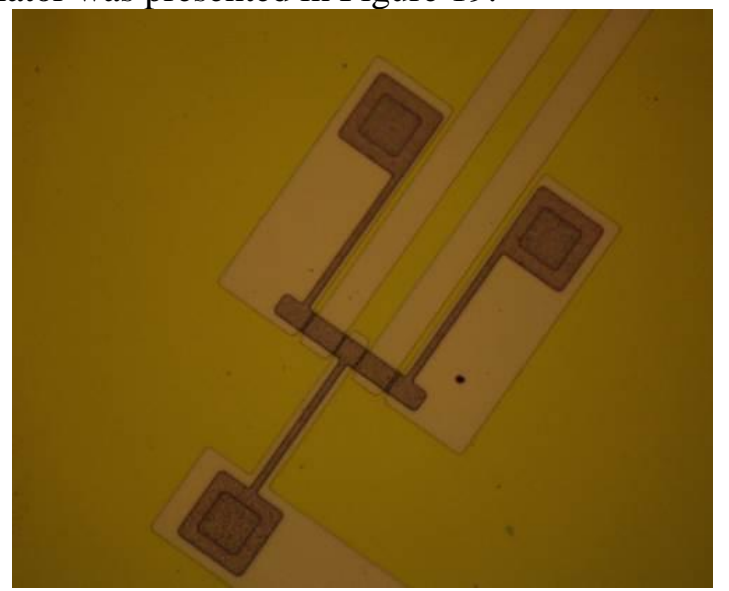

Figure 18. F-F beam resonator structure after releasing the sacrificial layer

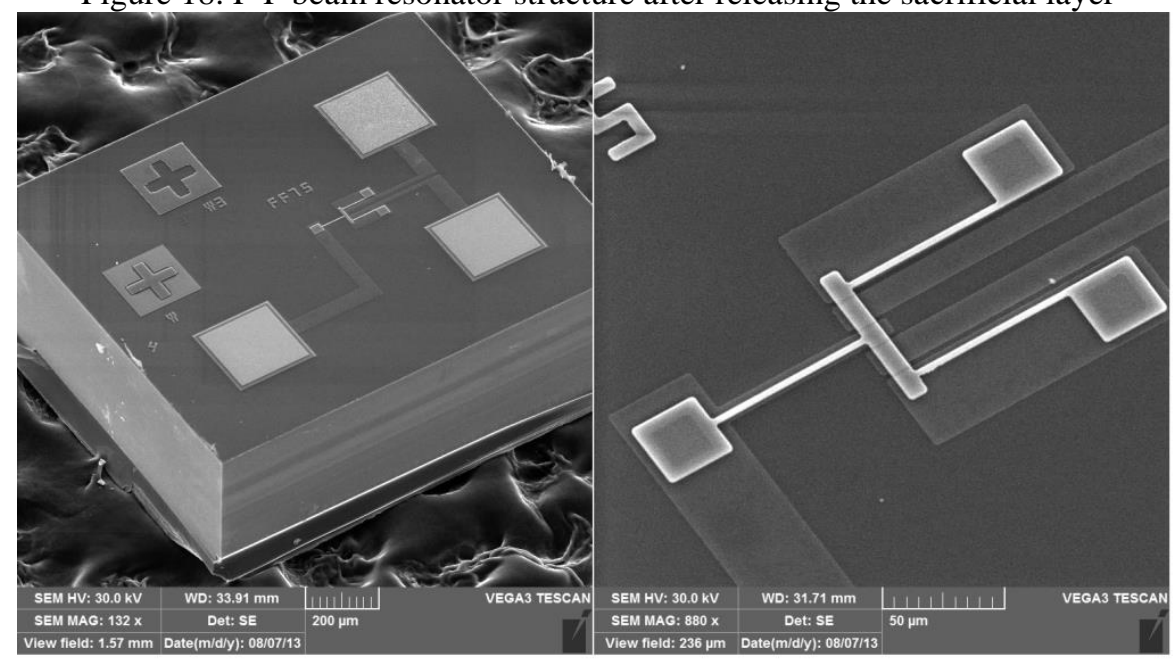

Figure 19. SEM images of F-F beam resonator after releasing the sacrificial layer

\section{CONCLUSIONS}

In this chapter, we have presented the designed for a 10-MHz F-F beam MEMS resonator. The theoretical calculations and FEM simulations were also employed to define the designed parameters. The surfacemicromachined technology is then proposed to fabricate the design. The process flow was briefly introduced from the layout design to the experimental fabricated device. It is indicated that the F-F beam MEMS resonator of this work has the capability fabrication using the available technology in the market. 
The MEMS-based surface-micromachined process with small size of the device, high quality factor as well as low motional impedance, which makes MEMS resonator more applicable

\section{ACKNOWLEDGMENT}

The authors would like to thank Bao Jingfu and the staffs of the Circuits and Systems Lab at the University of Electronic Science and Technology of China for their technical support and fabricating the device

\section{REFERENCES}

[1] Bannon III F. D., Clark J. R., and Nguyen C. T.-C., High Frequency Microelectromechanical IF Filters, IEEE Electron Devices Meeting, San Francisco, (1996) 773-776.

[2] Wang K., Yu Y., Wong A.-C., and Nguyen C. T.-C., VHF Free-Free Beam High-Q Micromechanical Resonators, 12th IEEE Int. Conf. on MEMS, Orlando, (1999) 453-458.

[3] Wang K., Ark-Chew Wong, and Nguyen C. T.-C., VHF Free-Free Beam High-Q Micromechanical Resonators, Journal of MEMS, 9(3) (2000) 347-360.

[4] Demirci M. U., Nguyen C. T.-C., Higher-Mode Free-Free Beam Micromechanical Resonators, IEEE Int. Freq. Cont. Symp., Tampa, (2003) 810-818.

[5] Bannon F. D., Clark J. R., and Nguyen C. T.-C., High-Q HF Microelectromechanical Filters, J. Solid-State Circuits, 35(4) (2000) 512-526.

[6] R. A. Johnson, Mechanical Filters in Electronics, New York: Wiley, 1983

\section{QUY TRÌNH ĐÓNG GÓI BỘ CỘNG HƯ⿱̛⿱N⿴囗十 MEMS DẠNG DẦM HAI ĐẦU TỰ DO ÚNG DỤNG CÔNG NGHỆ VI CƠ BỀ MẠT}

Tóm tắt. Bài báo trình bày công nghệ đóng gói cho bộ cộng hưởng MEMS ứng dụng công nghệ vi cơ bề mặt. Bộ cộng hưởng MEMS $10 \mathrm{MHz}$ dạng dầm hai đầu tự do được thiết kế để dao động ở chế độ thứ hai vì có nhiều ưu điểm so với chế độ cơ bản. Kết quả đạt được chỉ số chất lượng $Q$ cao khoảng 75000 , cải tiến so với kết quả đạt được bởi $\mathrm{K}$. Wang (khoảng 8400 ) trong thiết kế bộ cộng hưởng MEMS dạng dầm hai đầu tự do; và trở kháng thấp (khoảng $18 \mathrm{k} \Omega$ ). Công nghệ đóng gói vi cơ bề mặt được sử dụng như là tiêu chuẩn cơ bản cho thiết kế. Quy trình được mô tả chi tiết từ thiết kế layout đến sản phẩm đóng gói thực tế. Từ khóa. Bộ cộng hưởng MEMS, công nghệ vi cơ bề mặt, chế độ thứ hai, quy trình đóng gói.

Ngày nhận bài: 26/10/2018

Ngày chấp nhận đăng: 09/04/2019 